\title{
Personal Federal Tax Issues And The Affordable Care Act: Can Tax Penalties And Subsidized Premiums Provide Sufficient Incentives For Health Insurance Purchases
}

Alan D. Eastman, Indiana University of Pennsylvania, USA

Kevin L. Eastman, Georgia Southern University, USA

\begin{abstract}
The Patient Protection and Affordable Care Act of 2010 (ACA) includes many changes to the U.S. Federal Tax Code. The tax penalty imposed on individuals who choose to remain uninsured received extraordinary attention while the Supreme Court determined the constitutionality of the ACA. Now, the more relevant question is what impact the penalty may have on individual behavior.

This paper presents information that suggests the tax penalty may provide insufficient incentive for many individuals to purchase insurance, even with premium tax credits to reduce the cost for households earning up to $400 \%$ of the federal poverty limit. The ACA also reduces the tax benefit from the medical expense deduction by increasing the threshold amount from $7.5 \%$ of adjusted gross income to $10 \%$ of adjusted gross income. This may increase the after-tax cost of purchasing health insurance, especially for healthier individuals whose medical expenses (excluding insurance premiums) are below the threshold amount, increasing the incentive to forego the purchase of health insurance and to pay the penalty instead. An approach more consistent with the aims of the ACA is to eliminate the threshold amount but limit the deduction to lower-income taxpayers.
\end{abstract}

Keywords: Affordable Care Act; Tax Penalty; Premium Subsidy; Health Insurance

\section{INTRODUCTION}

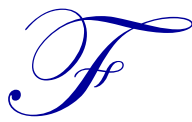

ederal tax provisions of the Patient Protection and Affordable Care Act of 2010 (ACA) include premium tax credits, cost-sharing subsidies, tax changes related to health insurance, and tax changes related to financing health reform. ${ }^{1}$ Perhaps the most publicized provision has been the tax penalty on individuals who are not covered by a qualifying health insurance plan beginning in $2014 .^{2}$ The tax penalty represents the stick in the carrot and stick approach to reducing the uninsured population. The carrot involves tax credits and cost sharing subsidies designed to make health insurance more affordable to lower-income Americans. Proponents of the ACA expect that broader participation, fewer uninsured individuals, and the resultant expansion of preventive care, as opposed to emergency care, will result in lower health insurance premiums for all.

\footnotetext{
${ }^{1}$ For an excellent summary of the tax provisions, as well as other aspects of the ACA, see Focus on Health Care: Summary of New Health Reform Law, publication \#8061 at the Kaiser Family Foundation website, www.kff.org.

${ }^{2}$ The tax penalty received intense scrutiny and was ultimately found to be constitutional by the Supreme Court in National Federation of Independent Business et al. v. Sebelius, Secretary of Health and Human Services, et al., decided June 28, 2012.
} 
Other parts of the ACA make it easier for individuals to purchase insurance, regardless of their medical condition, by reducing waiting periods and prohibiting insurance companies from denying coverage based on preexisting conditions. These changes to underwriting practices create an adverse selection problem as uninsured individuals may find it more beneficial to pay the tax penalty assuming they will not need significant medical treatment, but knowing that they can purchase insurance later if the need arises. The extent of the problem depends, in large part, on the size of the tax penalty relative to the cost of purchasing qualifying coverage. Analysis of the current penalty structure, with estimates of future premium costs, suggests that many individuals may be better off "gaming the system" by paying the penalty and waiting to purchase insurance only after a medical problem arises. If significant numbers of younger and relatively healthy individuals do not purchase insurance, then the expected benefits from expanding the insured population will not materialize.

The ACA also increases the threshold for deducting medical expenses from the current $7.5 \%$ of adjusted gross income (AGI) to $10 \%$ of AGI, effective January 1, 2013. The change is included as a revenue raiser for the federal government. Reducing the amount of deductible medical expenses results in higher after-tax costs for medical care, including the cost of health insurance, increasing the difference between the tax penalty for not having qualifying coverage, and the cost of such coverage. An approach more consistent with the rest of the ACA would be to allow the medical expense deduction for lower-income taxpayers at levels that would not exacerbate the adverse selection problem noted above, while remaining revenue neutral.

\section{PREMIUM CREDITS AND TAX PENALTIES: THE CARROT AND THE STICK}

To encourage broader participation in health insurance markets and reduce the number of uninsured individuals, the ACA provides refundable and advanceable premium credits for lower-income individuals to purchase health insurance. The tax credit is based on the premium associated with the applicable benchmark plan. ${ }^{3}$ The credit amount is equal to the difference between the benchmark plan premium and the family's expected contribution, which is determined as a percentage of income for specified federal poverty levels in 2014 as follows:

- $\quad$ Below 133 percent of poverty: 2.0 percent of income

- $\quad 133$ up to 150 percent of poverty: $3.0-4.0$ percent of income

- $\quad 150$ up to 200 percent of poverty: $4.0-6.3$ percent of income

- 200 up to 250 percent of poverty: $6.3-8.05$ percent of income

- $\quad 250$ up to 300 percent of poverty: $8.05-9.5$ percent of income

- 300 up to 400 percent of poverty: 9.5 percent of income ${ }^{4}$

Although the tax credit is based upon the benchmark plan, the family is not required to purchase that specific plan. If a taxpayer chooses a less expensive plan, then their contribution may be less than shown above, as illustrated by the following Treasury Department examples: ${ }^{5}$

\section{Example 1: Family Of Four With Income Of \$50,000, Purchases Benchmark Plan}

The premium tax credit is generally set based on the benchmark plan. The family's expected contribution is a percentage of the family's household income.

- Income as a Percentage of FPL

- Expected Family Contribution:

- Premium for Benchmark Plan: $\quad \$ 9,000$

- Premium Tax Credit: $\quad \$ 5,430(\$ 9,000$ - $\$ 3,570)$

- Premium for Plan Family Chooses: $\quad \$ 9,000$

- Actual Family Contribution: \$3,570

\footnotetext{
${ }^{3}$ The applicable benchmark plan is the second lowest cost silver plan in the rating area where the taxpayer resides and offered by the Exchange where the taxpayer enrolls in a qualified health plan. (Federal Register, May 23, 2012) A "silver plan" is a 70\% actuarial value plan.

${ }^{4}$ Families USA Foundation, 2010.

${ }^{5}$ U.S. Treasury, 8/12/11.
} 


\section{Example 2: Family Of Four With Income Of \$50,000, Purchases Less Expensive Plan}

If a family chooses a plan that is less expensive than the benchmark plan, the family will generally pay less, thereby creating an incentive to choose a less costly plan and reducing overall health care costs.

- Income as a Percentage of FPL 224\%

- Expected Family Contribution: $\quad \$ 3,570$

- Premium for Benchmark Plan: $\quad \$ 9,000$

- Premium Tax Credit: $\quad \$ 5,430(\$ 9,000-\$ 3,570)$

- Premium for Plan Family Chooses: $\quad \$ 7,500$

- Actual Family Contribution: $\quad \$ 2,070(\$ 7,500-\$ 5,430)$

Individuals who remain uninsured will be subject to a tax penalty beginning in 2014 . The tax penalty for each individual is the greater of $\$ 95$ or $1.0 \%$ of income in $2014, \$ 325$ or $2.0 \%$ of income in 2015 , and $\$ 695$ or $2.5 \%$ of income in 2016 and thereafter. ${ }^{6}$ Table 1 illustrates the tax penalty for individuals, and for a family of four, for 2014,2015 , and 2016:

Table 1: Tax Penalties In The ACA

\begin{tabular}{|l|c|c|c|c|}
\hline \multirow{2}{*}{} & \multicolumn{2}{|c|}{ Individuals } & \multicolumn{2}{c|}{ Family Of Four } \\
\cline { 2 - 5 } & $\begin{array}{c}\text { Income Above Filing } \\
\text { Threshold and }\end{array}$ & Penalty & $\begin{array}{c}\text { Income Above Filing } \\
\text { Threshold and }\end{array}$ & Penalty \\
\hline \multirow{2}{*}{2014} & Below $\$ 20,000$ & $\$ 95$ & Below $\$ 55,000$ & Above $\$ 55,000$ \\
\hline \multirow{2}{*}{2015} & Above $\$ 20,000$ & $1 \%$ of income & Below $\$ 75,000$ & $1 \%$ of income \\
\cline { 2 - 5 } & Below $\$ 25,000$ & $\$ 325$ & Above $\$ 75,000$ & $2.0 \%$ of income \\
\hline \multirow{2}{*}{2016} & Above $\$ 25,000$ & $2 \%$ of income & Below $\$ 110,000$ & $\$ 2,085$ \\
\cline { 2 - 5 } & Below $\$ 37,000$ & $\$ 695$ & Above $\$ 110,000$ & $2.5 \%$ of income \\
\hline
\end{tabular}

\section{PREMIUM SUBSIDIES}

The structure of the tax credits results in significant premium subsidies that increase as income decreases and also increase as the cost of the benchmark plan increases. Tables 2 and 3 show anticipated premium subsidy amounts and the percent of the total premium due to the insurance company that is paid by an insured individual, or insured family of four, in 2014. ${ }^{8}$ The percent of premium paid by insured individuals and families earning $300 \%$ of the federal poverty level is approximately five times greater than the percent of premium paid by those individuals and families earning $150 \%$ of the federal poverty level. Perhaps more importantly, the percent of premium paid by 20 -year-olds is two-and-a-half to three times greater than for 60 -year-olds. This results from the higher anticipated premium costs for older individuals. The subsidization of older Americans by younger, and presumably healthier, Americans can be achieved only if the participation rate for the younger and healthier population is increased. ${ }^{9}$

\footnotetext{
${ }^{6}$ Applicable income for purposes of calculating the tax penalty is defined as the amount by which an individual's household income exceeds the total of the personal exemption and standard deduction amount. The flat dollar amount of the penalty is reduced by one-half for dependents under the age of 18 and the penalty for a family is capped at $300 \%$ of the annual flat dollar amount. (Mulvey and Chaikind, 2012)

${ }^{7}$ Mulvey and Chaikind, 2012.

${ }^{8}$ Information in Tables 2 and 3 is generated using the Henry J. Kaiser Family Health Foundation's health reform subsidy calculator at http://healthreform.kff.org/SubsidyCalculator.aspx.

${ }^{9}$ The Employee Benefit Research Institute's estimates of the percentage of uninsured by gender and age in 2011 show that $23 \%$ of men age $18-20,31 \%$ of men ages $21-24$, and $32.1 \%$ of men ages $25-34$ are uninsured, compared to $14.1 \%$ of men ages $55-64$. For women, the comparable numbers are $19.4 \%$ for ages $18-20,26.4 \%$ for ages $21-24$, and $24.5 \%$ for ages $25-34$, compared to $15.0 \%$ for ages 55-64 (Fronstin, 2012).
} 
Table 2: Estimated Premium Subsidy Amounts For 2014

\begin{tabular}{|l|c|c|c|c|c|c|}
\hline \multirow{2}{*}{$\begin{array}{l}\text { Income \% Of } \\
\text { Poverty }\end{array}$} & \multicolumn{3}{|c|}{ Individuals } & \multicolumn{3}{c|}{ Family Of Four } \\
\cline { 2 - 7 } & Age 20 & Age 40 & Age 60 & Age 20 & Age 40 & Age 60 \\
\hline $100 \%$ & Medicaid & Medicaid & Medicaid & Medicaid & Medicaid & Medicaid \\
\hline $125 \%$ & Medicaid & Medicaid & Medicaid & Medicaid & Medicaid & Medicaid \\
\hline $150 \%$ & $\$ 2,700$ & $\$ 3,810$ & $\$ 9,481$ & $\$ 7,734$ & $\$ 10,725$ & $\$ 22,637$ \\
\hline $175 \%$ & 2,354 & 3,463 & 9,135 & 7,028 & 10,019 & 21,931 \\
\hline $200 \%$ & 1,941 & 3,050 & 8,722 & 6,188 & 9,179 & 21,091 \\
\hline $225 \%$ & 1,533 & 2,643 & 8,314 & 5,358 & 8,348 & 20,261 \\
\hline $250 \%$ & 1,075 & 2,185 & 7,856 & 4,425 & 7,416 & 19,328 \\
\hline $275 \%$ & 614 & 1,724 & 7,395 & 3,487 & 6,477 & 18,390 \\
\hline $300 \%$ & 112 & 1,221 & 6,893 & 2,463 & 5,454 & 17,366 \\
\hline $325 \%$ & 0 & 948 & 6,619 & 1,907 & 4,898 & 16,810 \\
\hline $350 \%$ & 0 & 674 & 6,346 & 1,351 & 4,341 & 16,254 \\
\hline $375 \%$ & 0 & 401 & 6,073 & 794 & 3,785 & 15,697 \\
\hline $400 \%$ & 0 & 128 & 5,800 & 238 & 3,229 & 15,141 \\
\hline
\end{tabular}

Table 3: Estimated Percentage Of The Total Premium Due

To The Insurance Company That Is Paid By The Insured Individual Or Family In 2014

\begin{tabular}{|c|c|c|c|c|c|c|}
\hline \multirow{2}{*}{$\begin{array}{l}\text { Income \% } \\
\text { Of Poverty }\end{array}$} & \multicolumn{3}{|c|}{ Individuals } & \multicolumn{3}{|c|}{ Family Of Four } \\
\hline & Age 20 & Age 40 & Age 60 & Age 20 & Age 40 & Age 60 \\
\hline $100 \%$ & Medicaid & Medicaid & Medicaid & Medicaid & Medicaid & Medicaid \\
\hline $125 \%$ & Medicaid & Medicaid & Medicaid & Medicaid & Medicaid & Medicaid \\
\hline $150 \%$ & 20 & 15 & 7 & 15 & 12 & 6 \\
\hline $175 \%$ & 31 & 23 & 10 & 23 & 17 & 9 \\
\hline $200 \%$ & 43 & 32 & 14 & 32 & 24 & 12 \\
\hline $225 \%$ & 55 & 41 & 18 & 41 & 31 & 16 \\
\hline $250 \%$ & 68 & 51 & 23 & 52 & 39 & 20 \\
\hline $275 \%$ & 82 & 62 & 27 & 62 & 47 & 24 \\
\hline $300 \%$ & 97 & 73 & 32 & 73 & 55 & 28 \\
\hline $325 \%$ & 100 & 79 & 35 & 79 & 60 & 30 \\
\hline $350 \%$ & 100 & 85 & 38 & 85 & 64 & 32 \\
\hline $375 \%$ & 100 & 91 & 40 & 91 & 69 & 35 \\
\hline $400 \%$ & 100 & 97 & 43 & 97 & 73 & 37 \\
\hline
\end{tabular}

\section{ADVERSE SELECTION AND "GAMING THE SYSTEM"}

Will the combination of tax credits to make health insurance more affordable and penalties on those who choose to remain uninsured provide sufficient incentives for the uninsured to purchase insurance? The answer may be "no" given other provisions of the ACA that exacerbate the adverse selection problem for health insurance providers. The ACA prohibits insurers from denying coverage based on pre-existing conditions and ensures consumers can purchase insurance without long waiting periods. Depending on the difference between the premium contribution and the penalty for remaining uninsured, an individual may reasonably decide to pay the tax penalty and only purchase insurance if his or her health deteriorates and medical treatment becomes necessary. Merrill Mathews, executive director of the Council for Affordable Health Insurance, refers to this situation as "gaming the system"; "The disparity between the cost of expensive coverage and the fine for not getting it encourages individuals buying their own coverage - those not in an employer plan - to game the system by paying the fine and remaining uninsured until they need coverage." ${ }^{10}$ Mathews cites two examples from Massachusetts, which passed legislation similar to the ACA in 2006, including the individual mandate:

- Charles Baker, former CEO of Harvard Pilgrim Health Care, noted that people were applying for health coverage after a medical condition developed, got the care they needed, and then dropped coverage. Between April 2008 and March 2009, 40\% of people who applied to Harvard Pilgrim stayed covered for less than 5 months, yet claims averaged \$2,400 per month - six times greater than expected.

\footnotetext{
${ }^{10}$ Mathews, Merrill. “Gaming the Health Insurance Mandate.” Investor's Business Daily, April 19, 2010.

318 Copyright by author(s) Creative Commons License CC-BY

2013 The Clute Institute
} 
- $\quad$ BCBS of Massachusetts experienced similar problems, reporting that in 2009 almost 1,000 people signed up for coverage for three months or less, with claims of more than \$1,000 each.

\section{COMPARISON OF PREMIUM CONTRIBUTION AND TAX PENALTY IN THE ACA}

Premium subsidies limit the amount lower income individuals and families must pay for health insurance, while tax penalties make it more costly to remain uninsured. Even with these incentives to purchase insurance, relatively healthy individuals may find it economically rational to pay the penalty and wait to purchase insurance only when a significant medical problem arises. If no medical expenses are incurred, then the total amount paid by an uninsured individual is the tax penalty, while an insured individual pays an insurance premium that is typically substantially more than the amount of the penalty. The economic consequence of staying uninsured until medical costs are imminent is that the individual then incurs both the penalty payment and the premium payment in the same period.

In this section, expected out-of-pocket healthcare costs (including penalties) are calculated for an individual and for a family of four. Minimum and maximum outlays are calculated for both those who buy insurance and for those who decide to remain uninsured until medical payments become necessary. The minimum outlay occurs if no medical expenses are necessary during the coverage period. An uninsured individual pays the penalty amount and an insured individual pays his or her subsidized premium. The maximum outlay occurs if medical expenses equal or exceed the maximum out-of-pocket expenditures specified in the ACA. An uninsured individual who delays purchasing insurance must pay both the penalty and the maximum out-of-pocket amount, which includes the subsidized premium. The insured individual pays the maximum out-of-pocket amount without incurring a penalty. Expected out-of-pocket healthcare costs are equal to the weighted average of the minimum and maximum amounts using the probability of remaining healthy (i.e., incurring no medical expenses) as the weight for the minimum amount, and assuming that otherwise the maximum amount will be reached, thereby having a probability of one minus the probability of remaining healthy.

Insurance premium contributions and maximum out-of-pocket expenses are estimated for income levels ranging from $150 \%$ to $800 \%$ of the federal poverty level. ${ }^{11}$ Penalty amounts are calculated for each income level for those who remain uninsured. Two scenarios are then compared. The first scenario assumes that no medical expenses are necessary during the coverage period. The cost of this scenario is either the penalty amount for those remaining uninsured or the premium contribution for those who purchase insurance. The second scenario is that medical expenses will equal or exceed the maximum out-of-pocket amount. The cost of this scenario for someone who is initially uninsured is the sum of the penalty plus the maximum out-of-pocket amount. The cost of this scenario for someone who purchases insurance at the beginning of the coverage period is simply the premium contribution plus the maximum out-of-pocket amount with no penalty for delaying the purchase of insurance. Whether it is beneficial to "game the system" depends upon the probability of staying healthy; i.e., making it through the coverage period without incurring medical expenses.

For example, consider a 20 year-old individual earning $150 \%$ of the federal poverty level in 2014 . This amounts to approximately $\$ 17,258$. The premium contribution is estimated to be $\$ 690$, with an additional maximum out-of-pocket cost of $\$ 2,083$. The penalty amount for this individual in 2014 is $\$ 95$. Suppose the individual remains uninsured. Under scenario one, total cost is equal to the $\$ 95$ penalty. Under scenario two, the total cost is the $\$ 95$ penalty plus the premium and maximum out-of-pocket expenses, or $\$ 2,868$. Now assume the individual purchases insurance at the beginning of the period. Under scenario one, the cost is the premium contribution of $\$ 690$. Under scenario two, the cost is the premium contribution plus the additional out-of-pocket expenses, or $\$ 2,773$. If we let $X$ equal the probability of staying healthy (requiring no expenditures for medical care), then we can set the expected value of each scenario equal to one another and solve for the probability of staying healthy that would make the individual indifferent between the two alternatives.

\footnotetext{
11 Premium contributions and maximum out-of-pocket amounts are estimated using the Henry J. Kaiser Family Health Foundation's health reform subsidy calculator at http://healthreform.kff.org/SubsidyCalculator.aspx
} 


$$
\text { Equation One: } \$ 95 \mathrm{X}+\$ 2,868(1-\mathrm{X})=\$ 690 \mathrm{X}+\$ 2,773(1-\mathrm{X})
$$

The solution is $X=14 \%$. This means that if the individual believes he/ she has more than a $14 \%$ chance of remaining healthy during the coverage period, the expected value of forgoing insurance and paying the penalty is greater than the expected value of buying insurance at the beginning of the coverage period. Tables 4 and 5 show the probability thresholds for various income and age levels for 2014-2016 for individuals and for families of four.

Table 4: Gaming The System - Probability Of Staying Healthy That Favors Remaining Uninsured For An Individual ${ }^{12}$

\begin{tabular}{|l|c|c|c|c|c|c|c|c|c|}
\hline \multirow{2}{*}{$\begin{array}{l}\text { Income } \\
\text { \% FPL }\end{array}$} & \multicolumn{3}{|c|}{ Age 20 } & \multicolumn{3}{|c|}{ Age 40 } & \multicolumn{3}{c|}{ Age 60 } \\
\cline { 2 - 10 } & $\mathbf{2 0 1 4}$ & $\mathbf{2 0 1 5}$ & $\mathbf{2 0 1 6}$ & $\mathbf{2 0 1 4}$ & $\mathbf{2 0 1 5}$ & $\mathbf{2 0 1 6}$ & $\mathbf{2 0 1 4}$ & $\mathbf{2 0 1 5}$ & $\mathbf{2 0 1 6}$ \\
\hline $150 \%$ & $14 \%$ & $47 \%$ & $100 \%$ & $14 \%$ & $47 \%$ & $100 \%$ & $14 \%$ & $47 \%$ & $100 \%$ \\
\hline $200 \%$ & $16 \%$ & $22 \%$ & $48 \%$ & $16 \%$ & $22 \%$ & $48 \%$ & $16 \%$ & $22 \%$ & $48 \%$ \\
\hline $250 \%$ & $12 \%$ & $25 \%$ & $30 \%$ & $12 \%$ & $25 \%$ & $30 \%$ & $12 \%$ & $25 \%$ & $30 \%$ \\
\hline $300 \%$ & $11 \%$ & $21 \%$ & $21 \%$ & $11 \%$ & $21 \%$ & $21 \%$ & $11 \%$ & $21 \%$ & $21 \%$ \\
\hline $400 \%$ & $14 \%$ & $27 \%$ & $34 \%$ & $11 \%$ & $21 \%$ & $26 \%$ & $11 \%$ & $21 \%$ & $26 \%$ \\
\hline $600 \%$ & $20 \%$ & $41 \%$ & $51 \%$ & $15 \%$ & $31 \%$ & $38 \%$ & $7 \%$ & $14 \%$ & $17 \%$ \\
\hline $800 \%$ & $27 \%$ & $54 \%$ & $68 \%$ & $20 \%$ & $41 \%$ & $51 \%$ & $9 \%$ & $18 \%$ & $23 \%$ \\
\hline
\end{tabular}

Table 5: Gaming The System - Probability Of Staying Healthy That Favors Remaining Uninsured For A Family Of Four

\begin{tabular}{|l|c|c|c|c|c|c|c|c|c|}
\hline \multirow{2}{*}{$\begin{array}{l}\text { Income } \\
\text { \% FPL }\end{array}$} & \multicolumn{3}{|c|}{ Age 20 } & \multicolumn{3}{c|}{ Age 40 } & \multicolumn{3}{c|}{ Age 60 } \\
\cline { 2 - 10 } & $\mathbf{2 0 1 4}$ & $\mathbf{2 0 1 5}$ & $\mathbf{2 0 1 6}$ & $\mathbf{2 0 1 4}$ & $\mathbf{2 0 1 5}$ & $\mathbf{2 0 1 6}$ & $\mathbf{2 0 1 4}$ & $\mathbf{2 0 1 5}$ & $\mathbf{2 0 1 6}$ \\
\hline $150 \%$ & $20 \%$ & $69 \%$ & $100 \%$ & $20 \%$ & $69 \%$ & $100 \%$ & $20 \%$ & $69 \%$ & $1 \%$ \\
\hline $200 \%$ & $10 \%$ & $33 \%$ & $71 \%$ & $10 \%$ & $33 \%$ & $71 \%$ & $10 \%$ & $33 \%$ & $71 \%$ \\
\hline $250 \%$ & $12 \%$ & $21 \%$ & $44 \%$ & $12 \%$ & $21 \%$ & $44 \%$ & $12 \%$ & $21 \%$ & $44 \%$ \\
\hline $300 \%$ & $11 \%$ & $15 \%$ & $31 \%$ & $11 \%$ & $15 \%$ & $31 \%$ & $11 \%$ & $15 \%$ & $31 \%$ \\
\hline $400 \%$ & $11 \%$ & $21 \%$ & $23 \%$ & $11 \%$ & $21 \%$ & $23 \%$ & $11 \%$ & $21 \%$ & $23 \%$ \\
\hline $600 \%$ & $15 \%$ & $31 \%$ & $38 \%$ & $12 \%$ & $23 \%$ & $29 \%$ & $6 \%$ & $12 \%$ & $15 \%$ \\
\hline $800 \%$ & $21 \%$ & $41 \%$ & $51 \%$ & $15 \%$ & $31 \%$ & $39 \%$ & $8 \%$ & $16 \%$ & $19 \%$ \\
\hline
\end{tabular}

The results suggest that tax penalties, especially in 2014 and 2015 , may be insufficient to overcome the adverse selection problem noted earlier. First, let's consider single individuals. In 2014, for only three of the twenty-one age/income combinations does the probability reach $20 \%$ or higher, with a maximum of $27 \%$. Fourteen of the twenty-one age/income combinations have probabilities under $15 \%$. In 2015, the probability levels are $25 \%$ or less for fourteen of the twenty-one age/income combinations.

Now let us consider the results for families of four. For all income levels, the highest probability indifference point in 2014 is $21 \%$. In 2015 , the probability levels are above $50 \%$ only for the lowest income group. This group enjoys the greatest premium subsidy, making it more likely they will benefit from purchasing insurance rather than risk the possibility of paying the penalty and then purchasing the insurance later. For incomes $200 \%$ of the federal poverty level and higher, the highest probability is $41 \%$. This outcome occurs for the youngest age group at the highest income level. This group would have the smallest difference between the premium contribution and tax penalty since the premium is expected to be lower for younger individuals while the penalty increases with income. All other probabilities are $33 \%$ or less, with an average probability of $22.5 \%$ and a median of $21 \%$.

Even the higher penalty levels in 2016 may be insufficient. First, let's consider single individuals. The youngest individuals with the lowest expected premiums still have indifference probabilities of between $21 \%$ and $34 \%$ in income ranges from $250 \%$ to $400 \%$ of the federal poverty level. In the forty-year-old age group, probabilities range from $21 \%$ to $38 \%$ over a wider income range of $250 \%$ to $600 \%$ of federal poverty level. For the oldest age group facing the highest premiums, probabilities range from $17 \%$ to $30 \%$ for incomes between $250 \%$ and $800 \%$ of the poverty level. Similar results can be seen for families of four, except that the lower probabilities typically begin at a higher income level $300 \%$ of poverty level compared to $250 \%$ of poverty level for

\footnotetext{
${ }^{12}$ In Tables 4 and 5, the percentages calculated for $150 \%$ of the federal poverty level in 2016 for all age groups exceeded $100 \%$. These amounts were reported at the maximum probability of $100 \%$.
} 
individuals). ${ }^{13}$

While it is not known what probability level of staying healthy will cause an individual to game the system, the stronger the person's belief that he will remain healthy, the greater the chance he will forgo health insurance. Survey data from 2011 shows that people who purchase their own health insurance in the private market or who are uninsured believe they are in relatively good health. The Employee Benefit Research Institute estimates that almost $73 \%$ of people with individually purchased health insurance report their health status as either excellent or very good. ${ }^{14}$ Over $59 \%$ of uninsured individuals also self-report their health status as either excellent or very good. Only $7.2 \%$ and $10.9 \%$, respectively, report their health status as fair or poor. ${ }^{15}$

\section{MEDICAL EXPENSE DEDUCTION}

Beginning in 2013, medical expenses must exceed $10 \%$ of adjusted gross income (AGI) to be tax deductible, up from a threshold of $7.5 \%$ of AGI in prior years. ${ }^{16}$ The change will increase the after-tax cost of purchasing health insurance for some taxpayers, thereby increasing the gap between the cost of insurance and the tax penalty for choosing to remain uninsured and making it more beneficial to game the system as described earlier. This is particularly true for healthy, higher income individuals. ${ }^{17}$ Assume the increase in the premium amount to be paid by an individual is equal to the additional tax caused by the increase in the threshold from $7.5 \%$ to $10 \%$ of AGI. For individuals with medical expenses reaching the new 10\% threshold, we recalculate the probabilities in Table 4 for income levels from $400 \%$ to $800 \%$ of the FPL. (These income levels correspond roughly to the $25 \%$ federal marginal tax bracket.) The results indicate a reduction in the probability of staying healthy that will encourage an individual to game the system, especially for younger individuals. For 20-year olds, the average reduction is 2.43 percentage points in 2014, 4.86 percentage points in 2015, and 6.08 percentage points in 2016. (Reductions range from 1.44 to 3.59 points for 40 -year olds and .47 to 1.18 points for 60 -year olds.) This outcome is inconsistent with the goal of other tax provisions of the ACA to use tax subsidies and tax penalties to encourage broader participation in health insurance markets. The intent of this change in the tax law is to raise revenue for the federal government.

If the goal is to limit deductions to raise revenue, an argument can be made to simply eliminate the medical expense deduction. "With the proposed increase in the floor...the pool of taxpayers eligible for the deduction will continue to shrink. Considering all of the efforts to tweak the law and then tweak it again, you have to wonder about the value of the medical expense deduction - is it time for it to go?"18

Another argument can be made that any limitation on the deduction of medical expenses is unfair to individuals without employer-provided healthcare (given the tax-favored status of employer-provided healthcare). Stephen Utz, professor of law at the University of Connecticut, states it this way:

An exclusion of the value of employer-provided health and accident insurance...plays a larger role than the medical expense deduction and costs the government a huge amount in foregone tax revenue. Self-employed individuals can deduct the full cost of health insurance against their income from the self-employment. The upshot is that only

\footnotetext{
${ }^{13}$ The results for 2015 and 2016 assume that premiums remain at 2014 levels, although penalties are increasing. If premiums increase at $10 \%$ per year, the indifference probabilities for 2016 would be approximately $20 \%$ lower, indicating an even greater chance that people will choose to remain uninsured and pay the tax penalty.

${ }^{14}$ It is reasonable to assume that the decision made by healthy individuals to purchase insurance is significantly influenced by current pre-existing conditions clauses. This incentive to purchase insurance will be eliminated in 2014. Under the ACA, beginning in 2014, Americans with pre-existing conditions cannot be denied coverage, cannot be charged significantly higher premiums, and cannot be subjected to longer waiting periods for coverage to begin.

${ }^{15}$ Employee Benefit Research Institute estimates of the Current Population Survey, March 2012 supplement.

${ }^{16}$ The threshold will remain at 7.5\% of AGI for individuals age 65 and older for tax years 2013-2016.

${ }^{17}$ People with high expected medical expenses are less likely to game the system because the probability of them purchasing insurance during the coverage period is high. Healthy individuals with lower expected medical expenses will be more influenced by the after-tax increase in insurance premiums. The after-tax increase in premiums is higher for individuals in higher marginal tax brackets. In 2013 , individuals with taxable income between $\$ 36,250$ and $\$ 87,850$ are in the $25 \%$ marginal federal tax bracket. For married filing jointly, the $25 \%$ bracket includes incomes from $\$ 72,500-\$ 146,400$.

${ }^{18}$ Erb, Kelly Phillips, "Deduct This: The History of the Medical Expenses Deduction," Forbes.com, 6/20/2011.
} 
employees without employer-provided health insurance are disfavored, mainly by the $7.5 \%$ AGI threshold for deducting health insurance premiums. ${ }^{19}$

Professor Utz argues that fairness in health care must be based on need. Although he does not advocate for the elimination of the $7.5 \%$ threshold, he certainly implies that it would be fairer if all health insurance premiums were paid with pre-tax dollars.

Given that the ACA subsidizes health insurance purchases for income levels up to $400 \%$ of the poverty level (currently $\$ 43,320$ for individuals and $\$ 88,200$ for a family of four), a more consistent approach for dealing with medical expense deductions may be to eliminate the threshold for lower-income taxpayers and eliminate the deduction altogether for higher-income taxpayers. Using IRS statistics for 2009 (the latest available), providing a $100 \%$ medical expense deduction for taxpayers with incomes up to $400 \%$ of the poverty level and eliminating the medical expense deduction for higher incomes would have required approximately the same tax expenditure by the government (just over $\$ 11$ billion in 2009) as the current 7.5\% threshold.

\section{CONCLUSION}

The ACA aims to reduce the uninsured population, broaden the base of participation in health insurance markets, and thereby provide healthcare at a lower cost. Younger and healthier individuals are needed to support the much larger subsidies for older insureds who require more care. If many remain uninsured due to adverse selection created by the elimination of underwriting tools such as pre-existing conditions limitations, then the opposite result may occur - higher premiums that increase the cost to the government of premium tax credits and cost subsidies, requiring tax increases and/or benefit reductions.

Individuals might decide to "game the system" by paying the tax penalty and remaining uninsured until they need medical attention, purchasing insurance to help pay their medical expenses and then dropping the insurance when they are healthy again. The incentive to game the system increases as the gap between the cost of purchasing health insurance and the amount of the tax penalty for not purchasing insurance gets larger. For the ACA to be successful, tax penalties likely need to be increased, especially in 2014 and 2015, but also for 2016 and beyond. Eliminating the threshold for medical expense deductions for lower-income taxpayers, perhaps up to 400\% of the federal poverty limit (to be consistent with other aspects of the ACA), and eliminating the medical expense deduction at higher income levels (to remain revenue neutral), could reduce the adverse selection problem at lower income levels and also result in more equitable tax policy (since higher income taxpayers are more likely to be receiving tax-favored health care).

\section{AUTHOR INFORMATION}

Alan Eastman is a Professor of Finance at Indiana University of Pennsylvania. Alan earned a doctorate in Risk Management and Insurance from Florida State University, with prior business experience in public accounting and small business management. His teaching and research interests include financial management, investments, insurance and insurance regulation. E-mail: aeastman@iup.edu (Corresponding author)

Kevin Eastman is a Professor of Finance at Georgia Southern University. He earned his Ph.D. in Managerial Science and Applied Economics at the Wharton School of Business of the University of Pennsylvania. His research areas of interest include insurance regulation, no-fault auto insurance, insurance market performance, and business ethics. E-mail: keastman@georgiasouthern.edu

\section{REFERENCES}

1. Americans for Tax Reform. "If the Mandate is a Tax, Obama Lied His Way into Office." www.atr.org, June 20, 2012.

\footnotetext{
${ }^{19}$ Utz, Stephen, "The Affordable Care Act and Tax Policy," Connecticut Law Review, April 2012. 
2. Bonacum, Leslie and Eric Scott. “Average Itemized Deductions (Data Based on Preliminary 2009 IRS Statistics)." 2012 CCH Whole Ball of Tax, CCH, http://www.cch.com/wbot2012/025AverageitemizedDeductions.sap, 2012.

3. Congressional Budget Office. "Estimates for the Insurance Coverage Provisions of the Affordable Care Act Updated for the Recent Supreme Court Decision.” July 2012.

4. Erb, Kelly Phillips. "Deduct This: The History of the Medical Expenses Deduction." www.forbes.com, June 20, 2011.

5. Fronstin, Paul. "Sources of Health Insurance and Characteristics of the Uninsured: Analysis of the March 2012 Current Population Survey." Issue Brief No. 376, Employee Benefit Research Institute, September 2012.

6. Health Reform Subsidy Calculator. The Henry J. Kaiser Family Foundation. http://healthreform.kff.org/subsidycaculator.aspx

7. Internal Revenue Service. "Health Insurance Premium Tax Credit, Final Regulations." Federal Register, Vol. 77, No. 100, May 23, 2012, pp. 30377-30400.

8. Internal Revenue Service. "Table 1.2 All Returns: Adjusted Gross Income, Exemptions, Deductions, and Tax Items, by Size of Adjusted Gross Income and by Marital Status, Tax Year 2009." http://www.irs.gov/uac/SOI-Tax-Stats-Individual-Statistical-Tables-by-Size-of-Adjusted-Gross-Income, 2012.

9. Internal Revenue Service. "Table 2.1 Returns with Itemized Deductions: Sources of Income, Adjustments, Itemized Deductions by Type, Exemptions, and Tax Items, by Size of Adjusted Gross Income, Tax Year 2009.” http://www.irs.gov/uac/SOI-Tax-Stats-Individual-Statistical-Tables-by-Size-of-Adjusted-GrossIncome, 2012.

10. "Lower Taxes, Lower Premiums: The New Health Insurance Tax Credit." Families USA Foundation, September 2010.

11. Matthews, Merrill. "Gaming the Health Insurance Mandate." Investor's Business Daily, April 19, 2010.

12. Mulvey, Janemarie and Hinda Chaikind. "Individual Mandate and Related Information Requirements Under ACA.” Congressional Research Service, July 2, 2012.

13. Roy, Avik. "CBO: 11 Million Uninsured Americans Will Be Subject to Obamacare's Individual Mandate 'Penalty Tax'." www.forbes.com, September 20, 2012.

14. "Summary of New Health Reform Law." Pulbication No. 8061, The Henry J. Kaiser Family Foundation, www.kff.org, April 15, 2011.

15. "Supreme Court Upholds Health Care Law; All Tax Measures Preserved.” A Special CCH Tax Briefing, Taxes - The Tax Magazine, CCH, August 1, 2012.

16. U.S. Treasury Department. "Treasury Lays The Foundation To Deliver Tax Credits To Help Make Health Insurance Affordable For Middle-Class Americans." http://www.treasury.gov/presscenter/Documents/36BFactSheet.pdf, August 12, 2011.

17. Utz, Stephen. "The Affordable Care Act and Tax Policy." Connecticut Law Review, April 2012. 


\section{$\underline{\text { NOTES }}$}

